5. Словник-довідник з професійної педагогіки / за ред. А. В. Семенової. Одеса, 2006. 362 с.

\section{REFERENCES}

1.Baranjuk,V.V.(2016).Formuvannia profesiino-komunikatymnoi kompetentnosti maibutnikh fakhivtsiv sotsialnoi roboty[Preparation of future social workers for application of technologies of medical and social work in professional activity]. Extended abstract of candidate's thesis. Khmelnitsky, 20p. [inUkrainian].

2. Danko, D. (2015). Pidhotovka maibutnikh sotsialnykh pratsivnykiv do zastosuvannia tekhnolohii medykosotsialnoi roboty $\mathrm{v}$ profesiinii diialnosti [Preparation of future social workers for application of technologies of medical and social work in professional activity]. Candidate's thesis. Ternopil, 278 p. [in Ukrainian].
3. Kalensky, A. A. (2016). Rozvytok profesiinopedahohichnoi etyky u maibutnikh vykladachiv spetsialnykh dystsyplin [Development of professionalpedagogical ethics for future teachers of special disciplines]. Doctor's thesis. Kyiv, 424 p. [in Ukrainian].

4. Nychkalo, N. G. (2004). Razvytye v Ukrayne yssledovanyi po problemam pedahohyky y psykholohyy professyonalnoho obrazovanyia na rubezhe stoletyi [Development in Ukraine of studies on pedagogy and psychology of vocational education at the turn of the century]. Kyiv, 67 p.[in Russian].

5. Slovnyk-dovidnyk z profesiinoi pedahohiky (2006). [Dictionary-reference book on professional pedagogy]. Odessa, 362 p. [in Ukrainian].

Стаття надійшла до редакції 10.05.2019

УДК 374.7:37.091.33(493)

DOI:

Олена Фучила, кандидат педагогічних наук, доцент кафедри іноземних мов Національного університету “Львівська політехніка"

\title{
МЕТОДИ НАВЧАННЯ ФУНКЦІОНАЛЬНОЇ ГРАМОТНОСТІ ДОРОСЛИХ У БЕЛЬГІЇ
}

У статті розглянуто принципи освіти дорослих, щчо їх покладено в основу навчання функиіональної грамотності дорослиху Бельгії; висвітлено особливості явища функиіональної грамотності дорослих у сучасному суспільстві економічно розвинутих краӥн, зокрема, Бельгії; відмінності навчання дорослих учнів та необхідність врахування їх у навчальному процесі для підвищення його ефективності. Виділено особливості організації навчання дорослих функиіональної грамотності у Бельгії як краӥні центральної Свропи та методи його здійснення, із окресленням можсливостей застосування досвіду Бельгії в системі освіти дорослих Украӥни в умовах глобалізаиії.

Ключові слова: Бельгія; глобалізація; освіта дорослих; функиіональна грамотність; методи навчання. Jim. 9.

Olena Fychyla, Ph.D.(Pedagogy), Associate Professor of the Foreign Languages Department Lviv Polytechnic National University

\section{METHODS OFTEACHING FUNCTIONAL LITERACY TO ADULTS IN BELGIUM}

The article considers some concepts of adult education in modern Belgium being one of European economically developed countries and, therefore, representing problems typical to most of them. The problem of functional illiteracy is more complex and harmful than illiteracy itself, since it can be less evident and less identifiable in modern world. Functionally illiterate adults are able to read, write and count, but they cannot apply their knowledge to solving the problems of their everyday life. This phenomenon is the feature of modern democratic societies where attending schools and acquiring secondary education is no more rigorous and spreads widely due to globalization opening boundaries between countries and continents.

Teaching functional literacy to adults requires techniques different from those used in the school environment. Firstly, adult learn more slowly and only when they are motivated and ensured that their knowledge could be of great practical value. Secondly, they remember their negative school experience, so teaching adults should be based on different principles than in school. It should use integrated syllabi which unite various skills and approaches in one lesson. Moreover, they can be changed according to the needs of adult learners after discussing them with teachers. Adults should be taught in small groups in the atmosphere of tolerance since the groups can be multinational.

The research has revealed that there are three methods of teaching functional literacy to adults in Belgium. They are analytical approach, global structural approach and reading approach which can be combined if necessary. All of them are directed towards developing skills particularly related to everyday life needs of participants. Since functional illiteracy tends to spread all over the world, it is necessary to eliminate the threat of its appearance in Ukraine, but if it occurs, the Belgian experience will help to lessen its influence on Ukrainian society.

Keywords: Belgium; globalization; adult education; functional literacy; teaching methods.

П остановка проблеми у загальному вигляді. Ключовим завданням системи освіти будь-якої держави $\epsilon$ підготовка громадян до повноцінного функціонування у соціумі. На початку XXI ст. у міжнародному освітньому просторі це завдання 


\section{МЕТОДИ НАВЧАННЯ ФУНКЦІОНАЛЬНОЇ ГРАМОТНОСТІ ДОРОСЛИХ У БЕЛЬГІЇ}

не тільки не втратило своєї актуальності, але набуло нового значення. Сучасний ринок праці промислово розвинених країн ставить надзвичайно високі вимоги до фахівців будь-якої галузі економіки [3]. Отже, повноцінне функціонування у соціумі вимагає певного рівня освоєних знань та сформованих навичок, тобто володіння функціональною грамотністю. Відповідно, відсутність або недостатність таких навичок призводить до явища функціональної неграмотності. Функціональна неграмотність дорослих може супроводжуватись відсутністю у них сертифікатів про завершення певних рівнів освіти i, як наслідок, неспроможністю здобувати подальшу освітута освоювати професійні навички, що відповідають вимогам сучасного ринку праці. Водночас кожна країна має свої особливості історичного та соціального розвитку, формування ставлення населення до навчання і грамотності зокрема. Це вимагає дослідження явища функціональної грамотності у контексті історичних політичних, соціальних та економічних умов кожної країни. Бельгії, промислово розвинутій країні, розташованій у центральній частині Свропи, притаманні риси розвитку європейського суспільства [7].

Глобалізація міжнародного економічного простору спричиняє взаємопроникнення освітніх тенденцій різних країн світу, причому як позитивних, так і негативних. Україна поряд із іншими європейськими державами є безпосереднім учасником цього процесу. Тому вивчення й аналіз причин виникнення функціональної неграмотності дорослих у сучасній Бельгії та досвіду організації навчання функціональної грамотності у межах системи освіти дорослих як елементу неперервної освіти у цій країні є важливим для формування стратегії запобігання поширенню явища функціональної неграмотності в Україні.

Аналіз основних досліджень і публікацій. Проблеми освіти дорослих викликали науковий інтерес у багатьох дослідників як за кордоном, так і в Україні. С.-А. Гоффіне, Д. ван Дамм здійснювали теоретичний аналіз функціональної неграмотності дорослих у Бельгії, Л. Вермеерш досліджувала проблему оцінювання грамотності дорослих, А. Ван Гехт аналізував передумови розвитку неграмотності дорослих у Бельгії, А. Мансо та Г. Бусетта описували проблему мовної інтеграції іммігрантів. Українські науковці Н. Бідюк, М. Бусько, М. Гаврилюк, Л. Лук'янова, 3. Магдач, проводили компаративні педагогічні дослідження систем освіти дорослих. Зміст, форми та методи навчання функціональної грамотності вивчали науковці О. Браун, Д. ван
Дамм, Л. Інгліш, С. Клюзер, А. Лукін, Л. Піплз, особливості навчального середовища освіти дорослих - С. Мерріам, І. де Мейер, Н. Мукан, О. Огієнко, але методи навчання функціональної грамотності дорослих у сучасній Бельгії ще не були досліджені.

Метою статті $\epsilon$ аналіз методів навчання дорослих функціональної грамотності 3 перспективи досвіду системи освіти дорослих Бельгії та визначити можливі шляхи застосування їх для навчання дорослих в Україні.

Виклад основного матеріалу. Використання навчальних методів для дорослих повинно бути творчим і гнучким. У Бельгії цю умову ефективного навчання дорослих втілюють у практику завдяки малому наповненню класів (кількість учнів у групі не перевищує 10 осіб). Учні також мають можливість опрацьовувати індивідуальні завдання завдяки гнучкому розкладу та можливості вибору опцій, ресурсів, швидкості прогресу у навчанні [2]. Другою умовою ефективного навчання дорослих $є$ розвиток взаєморозуміння, що грунтується на довірі між учнями та вчителем. Третьою умовою $€$ створення середовища навчання, відмінного від шкільного, оскільки багато учнів мають негативний досвід навчання у школі. В основному це стосується корінних бельгійців, а також іммігрантів другого покоління [8].

Оскільки методи навчання грамотності дорослих докорінно відрізняються від тих, що їх використовують ушкільній системі освіти, вчитель може за допомогою неформальних відносин із учнем, що встановлюються в процесі роботи, розкрити соціальний та індивідуальний світ учня i використати ці знання як основу для наповнення змістом наступних курсів навчання та створення умов для самовиховання [5]. "За самою суттю своєю самовиховання передбачає віру людини в людину, звертання до честі і гідності людини. Педагогічне керівництво самовихованням - це, насамперед, відносини між педагогом i вихованцем, пройняті глибокою взаємною вірою в добрі наміри" $[1,602]$. Отже, як для учнів, так і для вчителів курсів грамотності заняття 3 освоєння базових навичок $\epsilon$ місцем соціокультурного обміну.

У Бельгії існують три основних методи навчання функціональної грамотності. Це аналітичний підхід (англ. - analytical approach), глобальний структурний підхід (англ. - global structural approach) та читацький підхід (англ. reading approach). При аналітичному підході процес починається із навчання букв, які далі учні поєднують, утворюючи склади, та їх, своєю 
чергою, поєднують у слова. Таким чином, процес іде від простого до складнішого (не тільки від букв до слів, але також від простих до більш складних складів, від букв до дифтонгів тощо). Метою цього підходує навчити дорослих “розшифровувати” слова, аналізувати їх, розкладати їх на складові (букви чи склади), щоб потім знову скласти. Цей метод у системі навчання грамотності дорослих в основному використовують вчителі- волонтери, серед них - колишні вчителі початкової та середньої школи, що вийшли на пенсію [4].

Глобальний структурний підхід, на відміну від аналітичного підходу, грунтується на освоєнні слів як значимих одиниць (англ. - signifying entities); його метою $є$ заохотити учнів шляхом використання наочних засобів до засвоєння певної кількості слів, що складуть основу для подальшої роботи над розкладанням слів на морфологічні одиниці та укладанням і вивченням інших. Цей підхід частіше використовує оплачуваний викладацький персонал та невелика частина молодших волонтерів.

Читацький підхід є більш сучасною освітньою розробкою; він базується на ідеї: читати - означає надавати значення тексту. За його допомогою учнів навчають визначати значення тексту за допомогою формулювання гіпотез про його зміст та підтверджувати їх за допомогою різних ключів (структурних, синтаксичних тощо). Читання вважають комунікативною діяльністю, i, таким чином, використання навчальних матеріалів, які відповідають проблемам та зацікавленням учнів, $\epsilon$ необхідним. Прикладом цього методу $є$ навчальний набір під назвою "Коли неграмотні починають читати” (фр. - “Quand les illettrés deviennent lecteurs") [6]. Його, у більшості випадків, використовують вчителі із багатим досвідом навчання, які присвятили багато часу та зусиль оцінюванню різних методів та їхніх результатів на практиці. Цей метод набуває поширення у мережі курсів грамотності та курсів навчання вчителів.

Загалом, незалежно від обраного методу навчання, вчителі грамотності повинні брати до уваги індивідуальну зацікавленість учнів і їхні спеціальні потреби, використовувати тематичні матеріали, що відповідають щоденному оточенню учасників навчання, або матеріали, які приносять у клас учні [9].

Висновки. Проведений аналіз практичної реалізації навчання функціональної грамотності у системі освіти дорослих Бельгії дозволив 3'ясувати, що його змістовий компонент охоплює поєднання знань, навичок і вмінь базової (мовлення, читання, письмо, арифметична грамотність, комп'ютерна грамотність) із використанням соціального досвіду (пошук роботи, розв'язання побутових проблем) для повноцінного функціонування у суспільстві; особистісного розвитку та самоосвіти. Визначено, що функціональна грамотність передбачає наявність таких навичок і вмінь, як обмін ідеями та інформацією; використання чисел; використання інформаційних технологій; роботи з людьми та у команді; прийняття рішень; розв’язання проблем.

3'ясовано, що уБельгії навчання функціональної грамотності грунтується на використанні трьох основних підходів, а саме: аналітичний підхід від простого до складнішого; глобальний структурний підхід - освоєння слів як значимих одиниць 3 подальшим розвитковим використанням; читацький підхід - визначення значення тексту за допомогою формулювання гіпотез про його зміст.

Усі методи, а також їхні комбінації, використовують матеріали, пристосовані для функціонально неграмотних дорослих 3 метою допомоги у розв'язанні проблем їхнього щоденного життя через розвиток базових навичок та заохочення до читання для отримання інформації про світ та розвитку абстрактного мислення.

Перспективи подальших досліджень полягають у вивченні можливостей застосування методів навчання функціональної грамотності у системі освіти дорослих України при сумісності професійного, загальноосвітнього та культурного спрямування освіти дорослих, особливостей розвитку феномену “функціональна неграмотність дорослих” в умовах полікультурності та єдиного європейського освітнього простору.

\section{ЛІТЕРАТУРА}

1. Сухомлинський В. О. Вибрані твори: у 5 т. Київ, 1976. Т.2. 671 с.

2. Amalathas E. Learning to Learn in Further Education. Berkshire, 2010. 52 p.

3. Bauman Z. Liquid Times: Living in an Age of Uncertainty. Oxford, 2010. 128 p.

4. Blum A., Guerin-Pace F. Des Chiffres et des lettres. Paris, 2000. 191 p.

5. English L. M. Techniques for Teaching Adults: A Motivational and Reflective Approach. Dallas, 2006. 46 p.

6. Michel P. Quand les illettrés deviennent lecteurs. Bruxelles, 1987. $82 \mathrm{p}$.

7. Mukan N., Fuchyla O. Functional literacy learning in the system of adult education in Belgium. Advanced education. Kyiv, 2016. № 6. pp. 34-39.

8. Sociocultural Contexts of Language and Literacy [edited by B. Perez]. London, 2004. 424 p. 
9. Using Biographical and Life History Approaches in the Study of Adult and Lifelong Learning: European Perspectives [Edited by P. Alheit, A. S. Andersen, B. Merrill, L. West]. Frankfurt am Main, 2007. 310 p.

\section{REFERENCES}

1. Sukhomlynskyy, V. O. (1976). Vybrani twory u $5 t$. [Selected works in $5 \mathrm{v}$.]. Kyiv, Vol.2. [in Ukrainian].

2. Amalathas, E. (2010). Learning to Learn in Further Education. Berkshire. [in English].

3. Bauman, Z. (2010). Liquid Times: Living in an Age of Uncertainty. Oxford. [in English].

4. Blum, A. \& Guerin-Pace, F. (2000). Des Chiffres et des lettres [Numbers and letters]. Paris. [in French].

5. English, L. M. (2006). Techniques for
Teaching Adults: A Motivational and Reflective Approach. Dallas. [in English].

6. Michel, P. (1987). Quand les illettrés deviennent lecteurs [When the illiterate become readers]. Bruxelles. [in French].

7. Mukan, N., Fuchyla, O. (2016). Functional literacy learning in the system of adult education in Belgium, Advanced education, no.6, pp.34-39. [in English].

8. Perez, B. (Ed.). (2004). Sociocultural Contexts of Language and Literacy. London: Routledge. [in English].

9. Using Biographical and Life History Approaches in the Study of Adult and Lifelong Learning: European Perspectives (2007). Edited by P. Alheit, A. S. Andersen, B. Merrill \& L. West. Frankfurt am Main. [in English].

Стаття надійшла до редакції 23.04.2019

УДК 373.5.015.31:745/749

DOI:

Надія Кузан, кандидат педагогічних наук, доцент кафедри технологічної та професійної освіти Дрогобицького державного педагогічного університету імені Івана Франка

\section{ДЕКОРАТИВНЕ МИСТЕЦТВО ЯК ЗАСІБ ХУДОЖНЬО-ЕСТЕТИЧНОГО ВИХОВАННЯ УЧНІВ}

У статті наголошується на важливості застосування засобів декоративного мистецтвва у формуванні художньо-естетичної культури учнівської молоді; художньо-естетичне виховання розглядається як компонент естетичного виховання, оскільки передбачає вплив засобів мистецтва на особистість, акцентується увага на доиільності використання різних видів народних промислів, щзо пов'язано з регіональними особливостями украӥнців, природою, працею; підкреслюється, що формування художньоестетичного потенціалу учнів зумовлене впливом естетичних факторів довкілля та потребою залучення їх до творення дизайну навчальних приміщень в народному стилі.

Ключові слова: декоративне мистецтво; естетичне виховання; художньо-естетичне виховання учнів; творча діяльність; дизайн.

Jim. 10.

Nadiya Kuzan, Ph.D.(Pedagogy), Associate Professor of the Technological and Professional Education Department Drohobych Ivan Franko State Pedagogical University

\section{DECORATIVE ART AS MEANS OF ARTISTIC-AESTHETIC EDUCATION OF STUDENTS}

The article emphasizes the importance of the use of decorative arts in the formation of artistic and aesthetic culture of student youth; the emphasis is on the expediency of using different types of folk crafts (wood processing and decoration, ceramics, carpet weaving, lace, embroidery, easel painting, beading, etc.), which is connected with regional peculiarities of Ukrainians, by nature, by labor.

We consider artistic and aesthetic education as an integral part of aesthetic education, since it is about the formation of aesthetic culture through art. Artistic education in this context concerns the influence of means of art on the personality, the cultivation of artistic feelings, tastes, love of art, the ability to understand it, enjoy it, the ability to create. Aesthetic education is a deeper concept, because it touches on all human life, behavior, work, creativity, and relationships. Therefore, the purpose of artistic and aesthetic education is that, through perception, interpretation of works of art and practical artistic and creative activities, to form the students ' personal and value attitude towards reality, to develop aesthetic consciousness, general cultural and artistic competence, the ability to self-fulfillment.

Artistic and aesthetic education by means of decorative art involves the direct involvement of schoolchildren into work. By performing labor activities on a particular fishery, students experience the aesthetic bases of the 